\title{
ESTIMATION OF LEAF AREA INDEX IN CHESTNUT TREES USING MULTISPECTRAL DATA FROM AN UNMANNED AERIAL VEHICLE
}

\author{
Luís Pádua ${ }^{(1,2)}$, Pedro Marques ${ }^{(1,3)}$, Luís Martins ${ }^{(1,3)}$, António Sousa ${ }^{(1,2)}$, Emanuel Peres ${ }^{(1,2)}$, Joaquim J. \\ Sousa ${ }^{(1,2)}$ \\ ${ }^{1}$ University of Trás-os-Montes e Alto Douro, Vila Real, Portugal \\ ${ }^{2}$ Centre for Robotics in Industry and Intelligent Systems, INESC-TEC, Porto, Portugal \\ ${ }^{3}$ Centre for the Research and Technology of Agro-Environmental and Biological Sciences, Vila Real, \\ Portugal
}

\begin{abstract}
Individual tree segmentation is a challenging task due to the labour-intensive and time-consuming work required. Remote sensing data acquired from sensors coupled in unmanned aerial vehicles (UAV) constitutes a viable alternative to provide a quicker data acquisition, covering broader areas in a shorter period of time. This study aims to use UAV-based multispectral imagery to automatically identify individual trees in a chestnut stand. Tree parameters were estimated allowing its characterization. The leaf area index (LAI) was measured and was correlated with the estimated parameters. A good correlation was found for NDVI $\left(R^{2}=0.76\right)$, while this relationship was less evident in the tree crown area and tree height. This way, our results indicate that the use of UAV-based multispectral imagery is a quick and reliable way to determine canopy structural parameters and LAI of chestnut trees.
\end{abstract}

Index Terms - chestnut trees, leaf area index, unmanned aerial vehicles, multispectral imagery, individual tree segmentation

\section{INTRODUCTION}

In Portugal, chestnut trees (Castanea sativa Mill.) are an important species for forestry and agricultural purposes. In Portugal, the 34500 ha in the north region, representing $89 \%$ of its plantation surface and $88 \%$ of chestnut production [1]. However, several phytosanitary problems affect this species, which can cause severe production impacts and economic losses [2]. Typically, the detection of such problems is conducted through in-field observations, which are timeconsuming, laborious, have a reduced coverage, and requires specialized human resources.

Remote sensing techniques appears as a viable approach for the monitoring and mitigation of the risks of phytosanitary problems, helping to make chestnut farming a viable and sustainable business. Several studies were conducted using different remote sensing platforms and sensors in chestnut trees. Small format aerial photography from manned aircrafts were used to assess chestnut ink disease, abiotic diseases [3], [4] and chestnut blight [5]. Other studies used data from unmanned aerial vehicles (UAVs) to assess chestnut trees decline in different epochs [6], [7]. Aerial high resolution imagery were also used to evaluate three crown diameter and tree height [8].

The leaf area index (LAI), generally defined as the ratio of total leaf surface area to soil surface area [9], is an important parameter for estimating and evaluating various biological and physical vegetation processes [10] and is often used to assess plant health, nutrient supply and biomass [11]. Other studies showed that LAI is directly correlated to the outcomes obtained from UAV-based imagery, as vegetation indices, in vineyards [12], olives [13], wheat [14], forests [15], among others. By this way, in this study it is evaluated the usage of UAV-based multispectral imagery to analyse the relationship of different estimated parameters with the LAI in a chestnut stand.

\section{MATERIAL AND METHODS}

\subsection{Study area description}

The studied chestnut stand (Fig. 1) is located in a rural area in north-western Portugal. It has an area of approximately 0.4 ha and is composed of 52 trees from which 46 are chestnut trees.

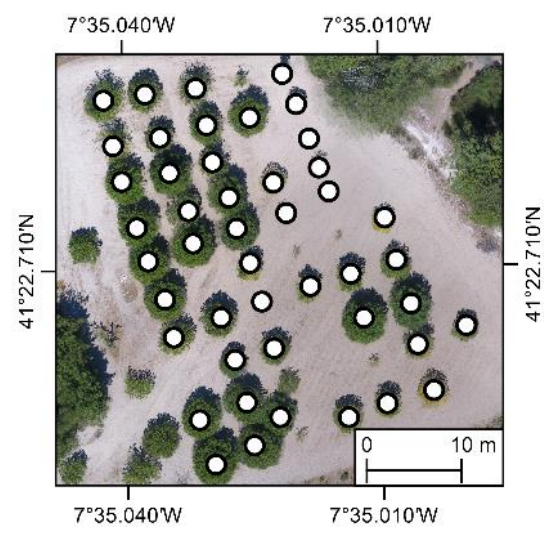

Fig. 1. Overview of the study area. Analysed trees are marked. 


\subsection{UAV-based data acquisition and processing}

The multi-rotor DJI Phantom 4 (DJI, Shenzhen, China) was used to acquire the remote sensed data. It comes equipped with a CMOS sensor (12.4 MP resolution), mounted in a 3axis gimbal, to acquire georeferenced RGB imagery. Parrot SEQUOIA (Parrot SA, Paris, France) was used to acquire multispectral imagery. This sensor is composed by a set of four cameras to individually acquire green, red, red-edge, and near infrared imagery, with $1.2 \mathrm{MP}$ resolution. For radiometric calibration, irradiance data is acquired during the flight and reflectance data is acquired using a calibration target.

The flight mission was performed on August $8^{\text {th }}, 2018$, in a double-grid pattern, at $60 \mathrm{~m}$ height, with a front and side imagery overlap of $80 \%$ and $70 \%$, respectively.

Photogrammetric processing of the acquired data was carried using the Pix4DMapper Pro (Pix4D SA, Lausanne, Switzerland), to generate an orthophoto mosaic, based on the RGB information. Digital elevation models (DSMs) and digital terrain models (DTMs) were generated from both RGB and multispectral imagery. Finally, the normalized difference vegetation index (NDVI) [16] was computed using the multispectral imagery. The outcomes driven from the RGB data were used only for visualization purposes. The obtained DSMs and DTMs were used to compute Canopy Height Models (CHM), which allows to obtain the height information from objects above the surface level. This process was accomplished in QGIS by subtracting the DTM to the DSM. The ground sample distance of the RGB imagery was approximately $2.6 \mathrm{~cm}$, and $6 \mathrm{~cm}$ for multispectral imagery.

\subsection{Individual tree estimation}

In chestnut stands, it is usual to find cases where the tree canopy tends to be too close to each other or even overlapped. To extract individual parameters, each tree must be isolated from the surrounding environment. This way, the CHM or vegetation indices could be both used as input in an image processing method for individual tree estimation. In this study the method proposed by Marques et al. [17] was used. The method was developed for individual monitoring of chestnut trees. It relies on the combined use of vegetation indices and CHM. Moreover, it enables the computation of several tree-related parameters, such as the tree canopy diameter, canopy area and tree height, along with values of remote sensed data.

\subsection{Leaf area index measurement}

LAI was measured in the field after the UAV data acquisition, using the LAI-2200C (LI-COR Biosciences, Nebraska, United States of America) with a view cap of $90^{\circ}$. One measurement was taken outside the canopy with direct sunlight and four measurements were taken around tree trunk in each quadrant.

\subsection{Accuracy estimation}

The acquired LAI data were compared with the different individual tree parameters, estimated from the UAV-based imagery. The comparison was carried by evaluating the histogram and the correlation with the LAI. The coefficient of determination $\left(R^{2}\right)$ was used to evaluate the data correlation.

\section{RESULTS}

\subsection{Data characterization}

The automatic segmentation and individual tree detection procedure enabled to detect each tree present in the analysed chestnut stand. In the case of this study, the CHM was used by considering only pixels with a height greater than $0.20 \mathrm{~m}$. This is the value normally used for CHM thresholding [10].

The total estimated canopy coverage of the chestnut trees was approximately $1200 \mathrm{~m}^{2}$. Ranging from $0.68 \mathrm{~m}^{2}$ to $42 \mathrm{~m}^{2}$ with a mean area of $21 \mathrm{~m}^{2}$. The estimated tree height ranged from $0.25 \mathrm{~m}$ to $7.5 \mathrm{~m}$, with a mean height value of $5.0 \mathrm{~m}$. Such low values can be related to the difficulty in estimate points during the photogrammetric processing for young trees with relatively low foliage [17]. As for the mean NDVI of the chestnut trees, it ranged from 0.27 to 0.86 and with a mean value of 0.72 . The LAI values measured in the field for the 46 chestnut trees, presented a minimum value of 0.10 and a maximum value 3.63 with a mean value of 1.58 .

\subsection{Leaf area index relationship with the parameters driven from the UAV data}

The relationships of the LAI with the estimated height, canopy area and mean NDVI value are presented in Fig. 2.

The best correlation was achieved in the mean NDVI of each chestnut tree $\left(R^{2}=0.76\right)$ with an exponential fitting defined by the following equation:

$$
\mathrm{LAI}=(0.0411 e)^{4.7568 \times \mathrm{NDVI}}
$$

The $R^{2}$ value of LAI and tree crown area was 0.64 , while for the LAI-height relationship it was 0.51 .

The correlation of LAI with NDVI was satisfactory and in line with other studies which evaluated this relationship in other species [12]-[15]. On the other hand, both tree crown area and tree height are not commonly analyzed in other studies. The results obtained for these parameters can be related to physiological disorders, as the ink disease or nutrient deficiencies, which can affect the leaf density, consequently, lowering the LAI when compared to the LAI of asymptomatic trees with a similar structure. Nevertheless, 
NDVI obtained from the UAV-based multispectral imagery poses as a good indicator of LAI in chestnut trees.
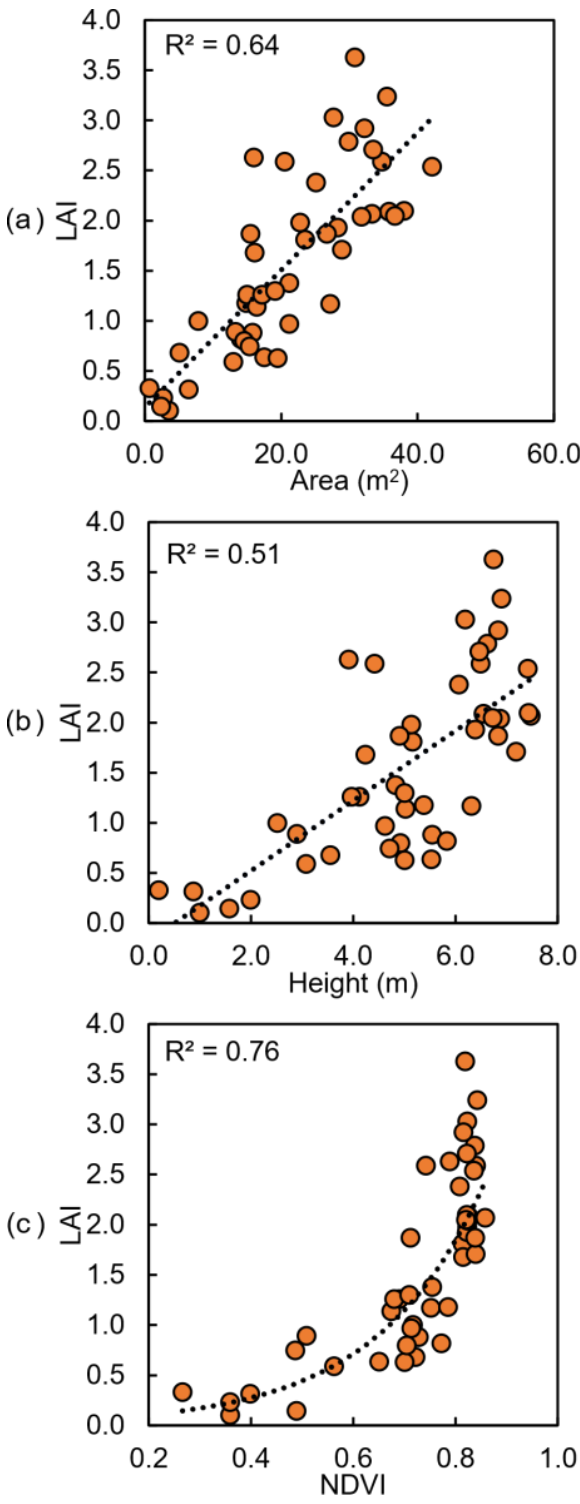

Fig. 2. Relationship of the leaf area index (LAI) with the tree canopy area, tree height and normalized difference vegetation index (NDVI) for 46 chestnut trees.

\section{CONCLUSIONS}

The results exposed in this work show the potential of UAVbased multispectral imagery to be employed in chestnut trees monitoring. The automatic method applied for the individual tree detection and estimation of different parameters proved to be effective in trees with different crown area and height. The mean tree crown NDVI allows to identify different vigour levels, and showed the best relationship with the measured LAI.

As future work, it is planned to evaluate more vegetation indices and to perform a multi-temporal analysis on the chestnut stand analysed in this study. This way, its growth and decline can be observed throughout the season, until chestnut harvesting. The assessment of phytosanitary problems will be also considered.

\section{ACKNOWLEDGMENTS}

Financial support provided by the Portuguese Foundation for Science and Technology FCT to Pedro Marques (PD/BD/150260/2019), under the Doctoral Programme "Agricultural Production Chains - from fork to farm" (PD/00122/2012) and to Luís Pádua (SFRH/BD/139702/2018).

\section{REFERENCES}

[1] Instituto Nacional de Estatística, I. P., Estatísticas Agrícolas 2018. Lisbon, Portugal: Instituto Nacional de Estatística, I.P., 2019.

[2] L. Martins, J. P. Castro, e E. Gouveia, «Biological control of chestnut blight in Portugal», Acta Horticulturae, vol. 1043, pp. 51-56, 2014.

[3] L. M. Martins, M. I. Lufinha, C. P. Marques, e C. G. Abreu, «Small format aerial photography to assess chestnut ink disease», Forest Snow and Landscape Research, vol. 73, pp. 357-360, 2001.

[4] A. Vannini, A. M. Vettraino, A. Fabi, A. Montaghi, R. Valentini, e C. Belli, «Monitoring ink disease of chestnut with the airborne multispectral system A.S.P.I.S.», Acta Horticulturae, n. 693, pp. 529-534, Out. 2005, doi: 10.17660/ActaHortic.2005.693.68.

[5] I. Ambrosini, L. Gherardi, M. L. Viti, G. Maresi, e T. Turchetti, «Monitoring diseases of chestnut stands by small format aerial photography», Geocarto International, vol. 12, n. 3, pp. 41-46, Set. 1997, doi: 10.1080/10106049709354595.

[6] L. M. Martins, J. P. Castro, R. Bento, e J. J. Sousa, «Chestnut health monitoring by aerial photographs obtained by unnamed aerial vehicle», Revista de Ciências Agrárias, vol. 38, n. 2, pp. 184-190, Jun. 2015.

[7] L. Pádua et al., «Multi-Temporal Analysis of Forestry and Coastal Environments Using UASs», Remote Sensing, vol. 10, n. 1, p. 24, Dez. 2017, doi: 10.3390/rs10010024.

[8] L. Pádua et al., «UAS-based Imagery and Photogrammetric Processing for Tree Height and Crown Diameter Extraction», em Proceedings of the International Conference on Geoinformatics and Data Analysis, New York, NY, USA, 2018, pp. 87-91, doi: 10.1145/3220228.3220241.

[9] D. J. Watson, «Comparative physiological studies on the growth of field crops: I. Variation in net assimilation rate and leaf area between species and varieties, and within and between years», Annals of botany, vol. 11, n. 41, pp. 41-76, 1947.

[10] C. E. Doughty e M. L. Goulden, «Seasonal patterns of tropical forest leaf area index and $\mathrm{CO} 2$ exchange», Journal of 
Geophysical Research: Biogeosciences, Fev. 2018, doi: 10.1029/2007JG000590@10.1002/(ISSN)21698961.AMAZONC1.

[11] C. Song, «Optical remote sensing of forest leaf area index and biomass», Progress in Physical Geography: Earth and Environment, vol. 37, n. 1, pp. 98-113, Fev. 2013, doi: $10.1177 / 0309133312471367$.

[12] I. Kalisperakis, C. Stentoumis, L. Grammatikopoulos, e K. Karantzalos, «Leaf area index estimation in vineyards from UAV hyperspectral data, 2D image mosaics and 3D canopy surface models», The International Archives of Photogrammetry, Remote Sensing and Spatial Information Sciences, vol. 40, n. 1, p. 299, 2015.

[13] G. Caruso et al., «High-resolution imagery acquired from an unmanned platform to estimate biophysical and geometrical parameters of olive trees under different irrigation regimes», PLOS ONE, vol. 14, n. 1, p. e0210804, Jan. 2019, doi: 10.1371/journal.pone.0210804.
[14] X. Yao et al., «Estimation of Wheat LAI at Middle to High Levels Using Unmanned Aerial Vehicle Narrowband Multispectral Imagery», Remote Sensing, vol. 9, n. 12, p. 1304, Dez. 2017, doi: 10.3390/rs9121304.

[15] J. Tian et al., «Comparison of UAV and WorldView-2 imagery for mapping leaf area index of mangrove forest», International Journal of Applied Earth Observation and Geoinformation, vol. 61, pp. 22-31, Set. 2017, doi: 10.1016/j.jag.2017.05.002.

[16] J. W. Rouse Jr., R. H. Haas, J. A. Schell, e D. W. Deering, «Monitoring Vegetation Systems in the Great Plains with Erts», NASA Special Publication, vol. 351, p. 309, 1974.

[17] P. Marques et al., «UAV-Based Automatic Detection and Monitoring of Chestnut Trees», Remote Sensing, vol. 11, n. 7, p. 855, Jan. 2019, doi: 10.3390/rs11070855. 